\title{
Control of Chronic Hepatitis B in China: Perspective of Diagnosis and Treatment
}

\author{
Yu Wang ${ }^{1}$; Min Wang'; Guanhua Zhang ${ }^{1}$; Xiaojuan $\mathrm{Ou}^{1}$; Hong Ma'; Hong You ${ }^{1}$; Jidong Jia ${ }^{1, \ldots}$
}

In the last three decades, China has made extraordinary effort and achieved great progress in the control of hepatitis B. Thanks to the adoption of universal administering of $\mathrm{HBV}$ vaccinations for newborns since 1992, the prevalence of hepatitis B surface antigen $(\mathrm{HBs} A \mathrm{~g})$ in the population born after 1992 decreased significantly resulting in a decline in the general population from $9.75 \%$ to about $6 \%$ (1). In the last 10 years, under the support of national major scientific research grants, many multicenter, randomized controlled trials (RCTs) have been conducted, generating more and more clinical evidence for antiviral therapy for chronic hepatitis B (CHB) (2). From 2005 to 2019, 4 editions of "Guidelines on the Prevention and Treatment of Chronic Hepatitis B" were jointly issued by 2 sister branches of the Chinese Medical Association including the Chinese Society of Hepatology and Chinese Society of Infectious Diseases (3-6). Sustained effort on continued medical education based in the clinical guidelines have raised the knowledge base of specialists and internists and improved the standard of care for CHB ( 7 ). Recently, the National Healthcare Secrurity Adminstration has conducted government negotiations to massively reduce the price of antiviral medicine. The improvement of the reimbursement policy together with increased patient accessibility and affordability for antiviral therapy have increased the uptake of antiviral therapy and improved the clinical outcomes (8). As a result, considerable progress has been made in diagnosis and treatment, making it possible to control hepatitis B in China.

\section{IMPROVEMENTS IN DIAGNOSTIC MODALITY}

In recent years, new serological markers, transient elastography (TE), and novel pathological criteria in the diagnosis of $\mathrm{CHB}$ have been extensively investiaged and increasingly used in China. Conventional HBV serological markers have been widely used in patients with $\mathrm{CHB}$ to establish the phases of $\mathrm{HBV}$ infection and guide antiviral therapy. Recently, the clinical utility of some novel markers have been investigated in patients with $\mathrm{HBV}$ infection. Quantitative $\mathrm{HBsAg}$ (qHBsAg) levels are correlated with intra-hepatic covalently closed circular DNA (cccDNA) and can predict treatment response (9). Baseline anti-HBc quantification (qAnti-HBc) may serve as a useful marker indicating ongoing host-immune activity against $\mathrm{HBV}$, with high levels of anti-HBc being used to predict the loss of hepatitis $B$ envelope antigen (HBeAg) (10-12), the efficacy of antiviral therapy (13-14), and the absence of HBV relapse after treatment cession (15). HBV core-related antigen $(\mathrm{HBcrAg})$ is a novel serum marker measuring composite viral protein and considered to be a surrogate marker of intrahepatic HBV cccDNA. A decrease in $\mathrm{HBcrAg}$ is related to the loss of HBeAg and HBsAg and the safe discontinuation of antivirus treatment. $\mathrm{HBcrAg}$ may also be helpful for predicting hepato cellular carcinoma (HCC) development. Serum pre-genomic RNA (pgRNA) transcribed from HBV cccDNA has a strong correlation with intrahepatic cccDNA and is considered to be an indirect marker of reservoir size $(16-17)$. These novel serum markers provide useful tools for better monitoring of disease progression and evaluation of the efficacy of antiviral therapy.

$\mathrm{TE}$ is a noninvasive tool with ease of operation, good repeatability, and reasonable accuracy for identifying liver fibrosis or early cirrhosis. A multicenter study validated the diagnostic performace of TE measured by FibroScan to stage liver fibrosis in a cohort of 469 Chinese patients with CHB (18). Another device for TE measurement (FibroTouch) has also comfirmed its clinical utility in a single-center prospective study including 435 chronic liver disease paitents including $237 \mathrm{CHB}$ paitents (19).

To quantitatively measure the degree of liver fibrosis in $\mathrm{CHB}$ patients, an automatic digital technique $\mathrm{q} F$ brosis has been investigated and shown promising results (20). In complementary to Ishak modified histology activity index (HAI) and Ishak fibrosis score, a new classification (Beijing Classification) has been 
proposed by Chinese investigators that further divides fibrosis beyond stage 3 into predominantly progressive, indeterminate, and predominately regressive (P-I-R score) to assess the dynamic changes in fibrosis preand post-antiviral therapy (21). Recently, one study using the Beijing classification found that liver fibrosis progression was associated with low serum HBV DNA level $(20-200 \mathrm{IU} / \mathrm{mL})$ at week 78 of nucleoside (nucleotide) analogue (NA) therapy, indicating that switching to or adding a more potent antiviral agent would benefit these patients (22).

\section{IMPROVEMENT IN CLINICAL STUDIES OF ANTIVIRAL THERAPY}

In the last decade, both the number and quality of clinical studies on treatment of HBV has dramatically improved (2). A large number of studies conducted by Chinese hepatologists showed that NA treatment can strongly suppress virus replication, improve liver histology, reduce the risk of complications and HCC progression, and reduce liver related all-cause mortality (23-27). An observational study showed that entecavir (ETV) monotherapy is associated with less virological breakthroughs and potentially higher HBV-DNA suppression than de novo combinationof lamivudine (LAM) and adefovirdipivoxil (ADV) during 3 years of treatment for naïve HBV-related compensated liver cirrhosis (28). Another real world study also demonstrated that ETV was efficacious and well tolerated through 48 weeks of treatment in a heterogeneous Chinese $\mathrm{CHB}$ population (29). A nationwide observational study showed that more than $50 \%$ of patients with CHB in Tier-2 city hospitals in China initially received ETV therapy, which not surprisingly was more effective than LAM-based treatments and associated with lower rate of treatment modification (30).

Effective viral suppression is necessary to reduce HCC development in cirrhotic patients (31). Tenofovir disoproxil fumarate (TDF) and ETV are first-line therapies, and in recent years, controversy exists on which one is superior to reduce the risk of HCC development. A meta-analysis was performed by Chinese researchers to clarify this issue with critical clinical and methodological considerations, showing that disparities in follow-up duration may be a key factor to influence the results (32).

Combination or sequential strategies based on the potent antiviral effect of NA and immune modulation of interferons (IFN) have been estenstively explored in China. Based on evidence from the "Optimising
$\mathrm{HBeAg}$ Seroconversion in $\mathrm{HBeAg}$-positive $\mathrm{CHB}$ Patients with Combination and Sequential Treatment of PegIFN alfa-2a and ETV" (OSST) study, "Switching to PegIFN a-2a in NUC treated CHB patients " (NEW SWITCH) study, Endeavor Study, and Anchor study, Chinese researchers proposed a roadmap for NA-Peg-IFN sequential therapy. In particular, in patients who achieved undectable HBV, the loss of $\mathrm{HBeAg}$, and a low level of $\mathrm{HBsAg}(<1,500$ $\mathrm{IU} / \mathrm{mL}$ ) under NA therapy, adding or swiching to PegIFN could yield a relatively higher rate of $\mathrm{HBsAg}$ loss ((and a low level of HBsAg $(<1,500 \mathrm{IU} / \mathrm{mL})$ under NA therapy, adding or swiching to Peg-IFN could yield a relatively higher rate of HBsAg loss (33-39). Furthermore, a prospective cohort study from China showed that Peg-IFN $\alpha$-2a-based therapy could reach high rates of HBsAg clearance $(29.8 \%$ and $44.7 \%$ at week 48 and 96, respectively) and seroconversion (20.2\% and $38.3 \%$ at week 48 and 96 , respectively) in patients diagnosed as inactive $\mathrm{HBsAg}$ carrier status $(40)$.

\section{UPDATE OF GUIDELINES AND OF EDUCATION ACTIVITY}

The guidelines on the Prevention and Treatment for Chronic Hepatitis B were first jointly published by the Chinese Society of Hepatology and Chinese Society of Infectious Diseases in 2005, and updated in 2010, 2015, and 2019. The 2019 version of the guidelines has two important changes (3). First, antiviral therapy is recommended if aminotransferase (ALT) is higher than 1 times instead of 2 times of the upper limit of normal levels (ULN, $40 \mathrm{IU} / \mathrm{L}$ for both men and women) for those with evidence of cirrhosis, intermediate degree of necroinflammation/fibrosis on non-invasive modality or on liver histology, older than 30 years, or family history of $\mathrm{HCC} /$ cirrhosis. This expansion of treatment indications will convey the benefit to antiviral therapy for larger populations, thereby reducing the risk of disease progression. Secondly, ETV, TDF, tenofoviralafenamide (TAF), and Peg-IFN $\alpha$ are recommended as the first-line choice for treatment of naïve patients, which is in line with recommendations from the World Health Organization (WHO), American Association for the Study of Liver Diseases (AASLD), Asian Pacific Association for the Study of the Liver (APASL) and European Association for the Study of the Liver (EASL); however, LAM, telbivudine (LdT), and ADV are not recommended. 
With the update of the guidelines, educational activities, and training programs were conducted to improve the standard of care (SOC) for $\mathrm{CHB}$ in China, especially in health resource limited areas. A 3year initiative titled "China Grassroots Hepatitis B Prevention \& Treatment Training Program” was implemented by the Chinese Society of Hepatology and Chinese Society of Infectious Diseases from 2015 to 2017. Totally, 58 training sessions of 1 -day courses covered nearly 10,000 primary care physicians from 31 provincial-level administrative divisions (PLADs). In 2018, the China Health Promotion Foundation launched the another 3-year hepatitis training program: "Poverty Alleviation and Health Preservation-Hepatitis Prevention and Treatment". In this program, the hepatologists and infectious disease doctors went to the remote and small cities in the 12 PLADs of western China to give the public education and clinical training to local doctors. In parallel, over 300 local physicians from the western part of China came to the 8 designated centers of excellence in Beijing, Shanghai, Guangzhou, and Chengdu for 3months of onsite clinical training.

\section{REIMBURSEMENT POLICY AND MASSIVE PRICE REDUCTIONS FOR ANTIVIRALS}

With economic and social development, the pricing and reimbursement policies have been steadily improved. Data from Beijing indicated that coverage of antiviral therapy by basic medical insurance since 2011 has reduced the risk of developing liver-related death for patients with $\mathrm{CHB}(8)$. The selection of a potent NA with high barrier to resistance as a first-line therapy, especially in areas with limited healthcare resources, may provide the best chance of achieving treatment goals (41). Until 3 years earlier, NA with high barrier to resistance like ETV and TDF had been much more expensive, so they were not widely used. To make a change, the government sectors, medical community, civil societies, and manufacturers have made joint efforts. Through government negotiation, the prices of TDF and TAF have reduced by $>50 \%$ and have been included in the basic medical insurance in the mainland of China. In 2019, the price of generic ETV and TDF has reduced to less than 10 yuan RMB per month in 11 PLADs. Indeed, data from the China Registry of Hepatitis B (CR-HepB) showed that among all $\mathrm{CHB}$ patients who received NA therapy, the proportion of those who received ETV and TDF had increased from $13.5 \%$ in 2003 to $79.7 \%$ in 2016 (42), and the proportions in cirrhotic paitents increased from $41.9 \%$ in 2010 to $92.8 \%$ in 2019 (43).

\section{PERSPECTIVE ON THE MASSIVE TEST- AND-TREAT STRATEGY}

Although the number of people with new HBV infections will become smaller, there are still an estimated 80 million people that are positive for HBsAg (44). According to the POLARIS modeling study, in the mainland of China, only around $20 \%$ of those chronically infected with HBV were actually diagnosed and and $10 \%$ of those who were eligible to be treated received treatment (45). Investment case modeling studies suggested that if we only treat the few millions of $\mathrm{CHB}$ who are already on the treatment, the HBV-related cirrhosis/HCC mortality will still be increasing over the next two decades; on the other hand, if we scale up test-and-treatment strategies and treat most or even all persons who need the treatment, the HBV-associated mortality will dramatically decline, which is cost-effective or even cost-saving (46). For example, if the treatment coverage increased from current practice $(12.5 \%)$ to $100 \%$ from 2018 , the numbers of chronic HBV infections, new HBV infections, and HBV-related deaths in 2035 would be reduced by $26.60 \%, 24.88 \%$, and $26.55 \%$, respectively, and in 2050, it would be reduced by $44.93 \%, 43.29 \%$, and $43.67 \%$, respectively (47). Therefore, we can conclude that implementations of $\mathrm{HBV}$ vaccination and increasing the test-and-treat coverage strategies are the most important and effective in controlling $\mathrm{CHB}$ in China.

\section{SUMMARY}

There is no doubt that China has made great achievements in the prevention and treatment of CHB. Predictably, in the future, the prevalence of $\mathrm{HBsAg}$ in the general population and HBV-related morbidity and mortality will further decline if we continue the current prevention measures and adopt massive testand-treat strategies. Finally, development of novel therapies aiming to clear $\mathrm{HBsAg}$ is under way. Therefore, we are confident that China will succeed in achieving the goal of eliminating hepatitis as a public health threat by 2030 .

doi: $10.46234 /$ ccdcw 2020.159

\# Corresponding author: Jidong Jia, jia_jd@ccmu.edu.cn. 


\begin{abstract}
${ }^{1}$ Liver Research Center, Beijing Friendship Hospital, Capital Medical University; Beijing Key Laboratory of Translational Medicine on Liver Cirrhosis; National Clinical Research Center for Digestive Diseases, Beijing, China.
\end{abstract}

Submitted: July 01, 2020; Accepted: July 18, 2020

\section{REFERENCES}

1. Liu J, Zhang SK, Wang QM, Shen HP, Zhang M, Zhang YP, et al. Seroepidemiology of hepatitis B virus infection in 2 million men aged 21-49 years in rural China: a population-based, cross-sectional study. Lancet Infect Dis 2016;16(1):80 - 6. http://dx.doi.org/10.1016/S14733099(15)00218-2.

2. Zeng N, Zou CL, He ZY, Ma H, Ou XJ, You H, et al. Systematic review on the reporting quality of randomized controlled trials in patients with hepatitis B or C in China. Int J Infect Dis 2018;67:58 64. http://dx.doi.org/10.1016/j.ijid.2017.11.011.

3. Chinese Society of Infectious Diseases, Chinese Medical Association, Chinese Society of Hepatology, Chinese Medical Association. The Guidelines of prevention and treatment for chronic hepatitis B (2019 Version). Chin J Hepatol 2019;27(12):938 - 61. http://dx.doi.org/10. 3760/cma.j.issn.1007-3418.2019.12.007. (In Chinese).

4. Hou JL, Wang GQ, Wang FS, Cheng J, Ren H, Zhunag H, et al. Guideline of prevention and treatment for chronic hepatitis B (2015 update). J Clin Transl Hepatol 2017;5(4):297 - 318. http://dx.doi.org/ 10.14218/JCTH.2016.00019.

5. Chinese Society of Hepatology, Chinese Medical Association, Chinese Society of Infectious Diseases, Chinese Medical Association. Guideline on prevention and treatment of chronic hepatitis B in China (2005). Chin Med J (Engl) 2007;120(24): 2159-73. https://pubmed.ncbi. nlm.nih.gov/18167196/.

6. Chinese Society of Hepatology and Chinese Society of Infectious Diseases, Chinese Medical Association. The guideline of prevention and treatment for chronic hepatitis B (2010 version). Chin J Hepatol 2011;19(1):13 - 24. http://dx.doi.org/10.3760/cma.j.issn.1007-3418. 2011.01.007. (In Chinese).

7. Huang JX, Guan ML, Balch J, Wu E, Rao HY, Lin A, et al. Survey of hepatitis B knowledge and stigma among chronically infected patients and uninfected persons in Beijing, China. Liver Int 2016;36(11):1595 603. http://dx.doi.org/10.1111/liv.13168.

8. Li M, Kong YY, Wu SS, Zhou JL, Wu XN, Wang L, et al. Impact of reimbursement program on liver-related mortality in patients with chronic hepatitis B in Beijing, China. J Dig Dis 2019;20(9):467 - 75. http://dx.doi.org/10.1111/1751-2980.12794.

9. Chan HLY, Wong VWS, Tse AML, Tse CH, Chim AML, Chan HY, et al. Serum Hepatitis B surface antigen quantitation can reflect hepatitis B virus in the liver and predict treatment response. Clin Gastroenterol Hepatol 2007;5(12):1462 - 8. http://dx.doi.org/10.1016/ j.cgh.2007.09.005.

10. Yuan Q, Song LW, Liu CJ, Li Z, Liu PG, Huang CH, et al. Quantitative hepatitis B core antibody level may help predict treatment response in chronic hepatitis B patients. Gut 2013;62(1):182 - 4 . http://dx.doi.org/10.1136/gutjnl-2012-302656.

11. Jia W, Song LW, Fang YQ, Wu XF, Liu DY, Xu C, et al. Antibody to hepatitis $\mathrm{B}$ core antigen levels in the natural history of chronic hepatitis B: a prospective observational study. Medicine (Baltimore) 2014; 93(29):e322. http://dx.doi.org/10.1097/MD.0000000000000322.

12. Song LW, Liu PG, Liu CJ, Zhang TY, Cheng XD, Wu HL, et al. Quantitative hepatitis B core antibody levels in the natural history of hepatitis B virus infection. Clin Microbiol Infect 2015;21(2):197 - 203. http://dx.doi.org/10.1016/j.cmi.2014.10.002.

13. Fan R, Sun J, Yuan Q, Xie Q, Bai XF, Ning Q, et al. Baseline quantitative hepatitis $\mathrm{B}$ core antibody titre alone strongly predicts HBeAg seroconversion across chronic hepatitis B patients treated with peginterferon or nucleos(t)ide analogues. Gut 2016;65(2):313-20. http://dx.doi.org/10.1136/gutjnl-2014-308546

14. Hou FQ, Song LW, Yuan Q, Fang LL, Ge SX, Zhang J, et al. Quantitative hepatitis B core antibody level is a new predictor for treatment response in $\mathrm{HBeAg}$-positive chronic hepatitis B patients receiving peginterferon. Theranostics 2015;5(3):218 - 26 . http://dx.doi.org/10.7150/thno.10636.

15. Chi H, Li ZD, Hansen BE, Yu T, Zhang XY, Sun J, et al. Serum level of antibodies against Hepatitis B core protein is associated with clinical relapse after discontinuation of nucleos(t)ide analogue therapy. Clin Gastroenterol Hepatol 2019;17(1):182 - 91.e1. http://dx.doi.org/10. 1016/j.cgh.2018.05.047.

16. Wang J, Shen T, Huang XB, Kumar GR, Chen XM, Zeng ZZ, et al. Serum hepatitis B virus RNA is encapsidated pregenome RNA that may be associated with persistence of viral infection and rebound. J Hepatol 2016;65(4):700 - 10. http://dx.doi.org/10.1016/j.jhep.2016.05.029.

17. Fan R, Zhou B, Xu M, Tan DM, Niu JQ, Wang H, et al. Association between negative results from tests for HBV DNA and RNA and durability of response after discontinuation of nucles( $\mathrm{t}$ )ide analogue therapy. Clin Gastroenterol Hepatol 2020;18(3):719-27.e7. http://dx.doi.org/10.1016/j.cgh.2019.07.046.

18. Jia JD, Hou JL, Ding HG, Chen GF, Xie Q, Wang YM, et al. Transient elastography compared to serum markers to predict liver fibrosis in a cohort of Chinese patients with chronic hepatitis B. J Gastroenterol Hepatol 2015;30(4):756 - 62. http://dx.doi.org/10. 1111 /jgh. 12840

19. Xu YM, Liu YH, Cao ZJ, Wang L, Li ZQ, et al. Comparison of FibroTouch and FibroScan for staging fibrosis in chronic liver disease: single-center prospective study. Dig Liver Dis 2019;51(9):1323 - 9 . http://dx.doi.org/10.1016/j.dld.2019.02.009.

20. Xu SY, Wang Y, Tai DCS, Wang S, Cheng CL, Peng QW, et al. qFibrosis: a fully-quantitative innovative method incorporating histological features to facilitate accurate fibrosis scoring in animal model and chronic hepatitis B patients. J Hepatol 2014;61(2):260 - 9. http://dx.doi.org/10.1016/j.jhep.2014.02.015.

21. Sun YM, Zhou JL, Wang L, Wu XN, Chen YP, Piao HX, et al. New classification of liver biopsy assessment for fibrosis in chronic hepatitis B patients before and after treatment. Hepatology 2017;65(5):1438 - 50. http://dx.doi.org/10.1002/hep.29009.

22. Sun YM, Wu XN, Zhou JL, Meng TT, Wang BQ, Chen SY, et al. Persistent low level of Hepatitis B virus promotes fibrosis progression during therapy. Clin Gastroenterol Hepatol 2020. http://dx.doi.org/10. 1016/j.cgh.2020.03.001.

23. Hou JL, Zhao W, Lee C, Hann HW, Peng CY, Tanwandee T, et al. Outcomes of long-term treatment of chronic HBV infection with entecavir or other agents from a randomized trial in 24 countries. Clin Gastroenterol Hepatol 2020;18(2):457 - 67.e21. http://dx.doi.org/10. 1016/j.cgh.2019.07.010.

24. Xu Y, Zhang YG, Wang X, Qi WQ, Qin SY, Liu ZH, et al. Long-term antiviral efficacy of entecavir and liver histology improvement in Chinese patients with hepatitis B virus-related cirrhosis. World J Gastroenterol 2015;21(25):7869 - 76. http://dx.doi.org/10.3748/ wjg.v21.i25.7869.

25. Su TH, Hu TH, Chen CY, Huang YH, Chuang WL, Lin CC, et al. Four-year entecavir therapy reduces hepatocellular carcinoma, cirrhotic events and mortality in chronic hepatitis B patients. Liver Int 2016;36(12):1755 - 64. http://dx.doi.org/10.1111/liv.13253.

26. Hou JL, Gao ZL, Xie Q, Zhang JM, Sheng JF, Cheng J, et al. Tenofovir disoproxil fumarate vs adefovir dipivoxil in Chinese patients with chronic hepatitis B after 48 weeks: a randomized controlled trial. J Viral Hepat 2015;22(2):85 - 93. http://dx.doi.org/10.1111/jvh.12313.

27. Liang XE, Gao ZL, Xie Q, Zhang JM, Sheng JF, Cheng J, et al. Longterm efficacy and safety of tenofovir disoproxil fumarate in Chinese patients with chronic hepatitis B: 5-year results. Hepatol Int 2019;13(3):260 - 9. http://dx.doi.org/10.1007/s12072-019-09943-6.

28. Wu XN, Zhou JL, Xie W, Ding HG, Ou XJ, Chen GF, et al. Entecavir monotherapy versus de novo combination of lamivudine and adefovir for compensated hepatitis B virus-related cirrhosis: a real-world prospective multicenter cohort study. Infect Drug Resist 2019;12:745 - 
57. http://dx.doi.org/10.2147/IDR.S185120.

29. Hou JL, Jia JD, Wei L, Zhao W, Wang YM, Cheng M, et al. Efficacy and safety of entecavir treatment in a heterogeneous $\mathrm{CHB}$ population from a 'real-world' clinical practice setting in China. J Viral Hepat 2013;20(11):811 - 20. http://dx.doi.org/10.1111/jvh.12115.

30. Jia JT, Tang H, Ning Q, Jiang JJ, Dou XG, Zhang MX, et al. Realworld evidence for nucleoside/nucleotide analogues in a 5-year multicentre study of antiviral-naive chronic hepatitis B patients in China: 52-week results. Antivir Ther 2018;23(3):201 - 9. http://dx.doi.org/10.3851/imp3205.

31. Zhang W, Wang XM, Wang Y, Zhao XY, Duan WJ, Wang QY, et al. Effective viral suppression is necessary to reduce hepatocellular carcinoma development in cirrhotic patients with chronic hepatitis B: results of a 10-year follow up. Medicine (Baltimore) 2017 96(44):e8454. http://dx.doi.org/10.1097/MD.0000000000008454.

32. Li M, Lv TT, Wu SS, Wei W, Wu XH, Ou XJ, et al. Tenofovir versus entecavir in lowering the risk of hepatocellular carcinoma development in patients with chronic hepatitis B: a critical systematic review and meta-analysis. Hepatol Int 2020;14(1):105 - 14. http://dx.doi.org/10. 1007/s12072-019-10005-0.

33. Ning Q, Wu D, Wang GQ, Ren H, Gao ZL, Hu P, et al. Roadmap to functional cure of chronic hepatitis B: an expert consensus. J Viral Hepat 2019;26(10):1146 - 55. http://dx.doi.org/10.1111/jvh.13126.

34. Ning Q, Han MF, Sun YT, Jiang JJ, Tan DM, Hou JL, et al. Switching from entecavir to PegIFN alfa-2a in patients with $\mathrm{HBeAg}$-positive chronic hepatitis B: a randomised open-label trial (OSST trial). J Hepatol 2014;61(4):777 - 84. http://dx.doi.org/10.1016/j.jhep.2014. 05.044.

35. Han MF, Jiang JJ, Hou JL, Tan DM, Sun YT, et al. Sustained immune control in HBeAg-positive patients who switched from entecavir therapy to pegylated interferon- $\alpha 2 \mathrm{a}: 1$ year follow-up of the OSST study. Antivir Ther 2016;21(4):337 - 44. http://dx.doi.org/10.3851/ IMP3019.

36. Hu P, Shang J, Zhang WH, Gong GZ, Li YG, Chen XY, et al. HBsAg loss with peg-interferon Alfa-2a in hepatitis $B$ patients with partial response to nucleos $(\mathrm{t})$ ide analog: new switch study. J Clin Transl Hepatol 2018;6(1):25 - 34. http://dx.doi.org/10.14218/JCTH.2017. 00072.

37. Wu D, Wang P, Han MF, Chen YP, Chen XY, Xia Q, et al. Sequential combination therapy with interferon, interleukin-2 and therapeutic vaccine in entecavir-suppressed chronic hepatitis B patients: the endeavor study. Hepatol Int 2019;13(5):573 - 86. http://dx.doi.org/ 10.1007/s12072-019-09956-1.

38. Gao ZL, Zhu X, Lin BL, Yi JH, GAo WJ, Chen YM, et al. The optimizing treatment of peg interferon Alfa in $\mathrm{HbeAg}$ negative chronic hepatitis B patients with low level HBsAg: a multicenter real world study (Interferon Cure Study, I CURE Study). Hepatology 2018;68(S1): 246A. https://aasldpubs.onlinelibrary.wiley.com/doi/epdf/ 10.1002/hep.30257.

39. Xie Q, Cai W, Ouyang LJ, Gao YQ, Li SB, Xu J, et al. Effectiveness of response-guided peginterferon Alfa-2a therapy in nucleos $(t)$ ide analogues treated patients with $\mathrm{HBeAg}$-positive chronic hepatitis $\mathrm{B}$ : interim analysis of a prospective, multicenter, randomized study. Hepatology 2018;68(S1): 232A. https://aasldpubs.onlinelibrary. wiley.com/doi/epdf/10.1002/hep.30257.

40. Cao ZH, Liu YL, Ma LN, Lu JF, Jin Y, Ren S, et al. A potent hepatitis $B$ surface antigen response in subjects with inactive hepatitis B surface antigen carrier treated with pegylated-interferon alpha. Hepatology 2017;66(4):1058 - 66. http://dx.doi.org/10.1002/hep.29213.

41. Gish R, Jia JD, Locarnini S, Zoulim F. Selection of chronic hepatitis B therapy with high barrier to resistance. Lancet Infect Dis 2012;12 (4):341 - 53. http://dx.doi.org/10.1016/S1473-3099(11)70314-0.

42. Shan S, You H, Niu JQ, Shang J, Xie W, Zhang YX, et al. Baseline characteristics and treatment patterns of the patients recruited to the China registry of Hepatitis B. J Clin Transl Hepatol 2019;7(4):322 - 8. http://dx.doi.org/10.14218/JCTH.2019.00052.

43. Kong YY, Wei W, Shan S, Ma H, Ou XJ, Xu XY, et al. Clinical profiles and treatment patterns of patients with HBV-related liver cirrhosis. Chin Hepatol 2020;25(2):123-7. http://dx.doi.org/10.3969/j.issn. 1008-1704.2020.02.012. (In Chinese)

44. Schweitzer A, Horn J, Mikolajczyk RT, Krause G, Ott JJ. Estimations of worldwide prevalence of chronic hepatitis B virus infection: A systematic review of data published between 1965 and 2013. Lancet 2015;386(10003):1546 - 55. http://dx.doi.org/10.1016/S0140-6736 (15)61412-X

45. The Polaris Observatory Collaborators. Global prevalence, treatment, and prevention of hepatitis B virus infection in 2016: a modelling study. Lancet Gastroenterol Hepatol 2018;3(6):383 - 403 . http://dx.doi.org/10.1016/S2468-1253(18)30056-6.

46. Nayagam S, Chan P, Zhao K, Sicuri E, Wang XC, Jia JD, et al. Investment case for a comprehensive package of interventions against Hepatitis B in China: applied modeling to help national strategy planning. Infect Dis 2020. http://dx.doi.org/10.1093/cid/ciaa134.

47. Zu J, Li ML, Zhuang GH, Liang PF, Cui FQ, et al. Estimating the impact of test-and-treat strategies on hepatitis B virus infection in China by using an age-structured mathematical model. Medicine (Baltimore) 2018;97(16):e0484. http://dx.doi.org/10.1097/MD.000000 0000010484 . 